\title{
"EXAMINANDO DRAGÕES": O ANTI ANTIRRELATIVISMO COMO PROPOSTA AO CONTRASSENSO DA DISCUSSÃO CLÁSSICA ENTRE O UNIVERSALISMO E RELATIVISMO CULTURAL DOS DIREITOS HUMANOS
}

\author{
Pedro Lucas Campos de Medeiros*
}

\section{RESUMO}

Esta pesquisa analisa os fundamentos dos Direitos Humanos sob o viés da clássica discussão entre o universalismo e relativismo, apresentando um contrassenso a partir do conceito de anti anti-relativismo, proposto por Clifford Geertz. Neste sentido, investigase o anti anti-relativismo como forma de resgatar valores antropológicos na discussão relativista, superando os paradoxos do relativismo e universalismo e buscando compreender de que modo o anti anti-relativismo pode ampliar o horizonte interpretativo sobre o relativismo cultural dos Direitos Humanos. Trata-se de um estudo de natureza bibliográfica, valendo-se do método dedutivo para alcançar o resultado.

Palavras-Chave: Direitos Humanos; Fundamentação; Universalismo; Relativismo; Anti antirrelativismo.

\section{"EXAMINING DRAGONS": THE ANTI ANTI-RELATIVISM AS A PROPOSAL TO THE CLASSIC DISCOURSE BETWEEN UNIVERSALISM AND CULTURAL RELATIVISM OF HUMAN RIGHTS}

\begin{abstract}
This research analyzes the foundations of Human Rights under the bases of the classic discussion between universalism and relativism, presenting a counter-opinion from the concept of anti-relativism proposed by Clifford Geertz. In this sense, anti-relativism is investigated as a way of recovering anthropological values in relativistic discussion, overcoming the paradoxes of relativism and universalism and seeking to understand how the anti-relativism can broaden the interpretive horizon on the cultural relativism of Rights Humans. It is a bibliographical study, using the deductive method to achieve the result. This is a bibliographic research, using the deductive method to achieve the result.
\end{abstract}

Keywords: Human Rights; Grounds; Universalism; Relativism; Anti anti-relativism;

\section{INTRODUÇÃO}

A emergência dos direitos humanos no contexto geopolítico Pós-Segunda Guerra Mundial, demonstrou a necessidade em superar os desafios filosóficos acerca de sua fundamentação. Fortemente reivindicados desde a Revolução Francesa, que resultou na

\footnotetext{
* Mestrando em Ciências Jurídicas no Programa de Pós-graduação em Ciências Jurídicas da UFPB, na área de concentração em Direitos Humanos. Bolsista CAPES. Professor de Direito. Graduado em Direito pela UFERSA. Email: pedrolcm@live.com
} 
publicação da Declaração do Homem e do Cidadão, são atualmente instrumentos de luta, 70 anos após a publicação da Declaração Universal dos Direitos Humanos.

A partir da necessidade de reconhecer direitos fundamentais inerentes a condição de ser humano, os direitos humanos tornaram-se fontes de reinvindicação, sendo incorporado as lutas de minorias nacionais e étnicas para o seu reconhecimento e exequibilidade diante dos ordenamentos internos e dos mecanismos internacionais de proteção.

Nesse sentido, em meio a construção histórica dos direitos humanos, sua universalidade é uma das formas primárias de garantir que qualquer pessoa seja sujeito de direito, possuindo legitimidade para buscar sua efetividade perante ao Estado e a comunidade internacional. Todavia, essa universalidade é questionada sob o ponto de vista do relativismo cultural, que defende os direitos humanos como produtos culturais, construídos no seio da comunidade que possui valores específicos e, a partir dessas peculiaridades, desenvolve seus próprios conceitos acerca do que é bom ou mal, certo ou errado.

Diante desse pressuposto, os direitos humanos se deparam com o seguinte desafio: como conceber direitos universais, inerentes a condição de ser humano, preservando sua cultura, tradição, rituais, costumes e valores, sem impor uma perspectiva ocidental do que é certo? Como proteger os direitos humanos, a partir de uma posição relativista que aceita qualquer prática alheia sob o argumento da manifestação cultural? Como proteger culturas diante de práticas nocivas aos direitos humanos, indo além do "modo de ver as coisas"?

Assim, "Examinar dragões, não domesticá-los ou abominá-los, nem afogá-los em barris de teoria" é a proposta de Geertz quando apresenta sua concepção de anti antirrelativismo que traz valores antropológicos para o debate clássico, discutindo o anti relativismo, sem necessariamente aceitar o relativismo, nem o universalismo. Uma ideia que, a priori, parece confusa, porém, quando analisada sob a ótica das dificuldades em estabelecer fundamentos universais, e ao mesmo tempo, quando nota-se a necessidade em resgatar o debate antropológico na vertente relativista, o anti antirrelativismo torna-se consistente como uma alternativa à discussão clássica entre universalismo e relativismo cultural. 
Neste sentido, o problema visa responder ao seguinte questionamento: a partir das críticas feitas por Geertz, de que modo o anti antirrelativismo pode ampliar o horizonte interpretativo sobre o relativismo cultural dos Direitos Humanos?

$\mathrm{Na}$ primeira parte aborda-se os pressupostos acerca dos fundamentos dos direitos humanos, como questão fundamental para o entendimento dos paradoxos centrais da discussão entre o universalismo e relativismo dos direitos humanos. Na segunda parte, discutiremos o relativismo cultural e os direitos humanos como produtos culturais, como forma de construir os paradoxos teóricos da discussão clássica. Por fim, apresenta-se uma posição terciária defendida por Geertz, como uma proposta teórica de ampliar esse horizonte interpretativo e, sobretudo, relevar o debate considerando a peculiaridade das culturas e a forma dos direitos humanos concebê-las, respeitando a produção cultural em consonância com valores morais vinculados a natureza humana, e valorizando a perspectiva interdisciplinar fornecida por outras ciências.

Este trabalho apresenta-se, portanto, como sendo de natureza bibliográfica, valendo-se do método dedutivo para partir do geral (conceito de universalismo e relativismo) e, posteriormente, ingressar nos aspectos específicos do anti antirrelativismo de Geertz e suas respectivas críticas.

\section{PRESSUPOSTOS ACERCA DOS FUNDAMENTOS DOS DIREITOS HUMANOS}

Os paradoxos centrais das discussões acerca dos Direitos Humanos partem de sua fundamentação. E não apenas em relação a discussão teórica sobre qual seriam as bases dessa fundamentação, mas também acerca da incógnita sobre a possibilidade de existência de um fundamento absoluto que possa contemplar todas as categorias de direitos fundamentais.

Poderíamos, portanto, pensar em um parâmetro comum de fundamentação que contemple a noção de direitos humanos? Esse parâmetro deve ser universal ou relativizado de acordo com o contexto cultural? Como preservar direitos inerentes a natureza humana, enquanto a própria razão questiona o conceito de natureza humana?

Esses questionamentos acompanham o debate filosófico dos direitos humanos, onde a ciência jurídica inicia seu processo de investigação, utilizando-se de outras ciências sociais, como a história e antropologia, para definir fundamentos dos direitos 
humanos que permitam sua exequibilidade, não apenas pela proteção do Estado ou pela construção do consenso internacional, mas pela condição de ser humano, e de ter garantias fundamentais por força disso.

Partindo de críticas a ilusão de existência de um fundamento absoluto para os direitos humanos, Bobbio (1992, p. 36-39) elenca as seguintes dificuldades para estabelecer esse fundamento:

1) A vagueza da expressão "direitos do homem", que pela natureza semântica, denota dificuldades em estabelecer referências e contornos nítidos.

2) Os direitos do homem possuem variações de acordo com as classes que compõem a sociedade. Dessa forma, o processo de modificação desses direitos depende das classes que estão no poder e dos mecanismos disponíveis para sua realização. A relevância do fator histórico no processo de construção de direitos impossibilita a existência de um fundamento absoluto.

3) Há diversas pretensões entre os direitos dos homens, sendo estes, portanto, heterogêneos. Essa diversidade faz com que direitos fundamentais dispostos em uma mesma Declaração possam ser incompatíveis entre si. O resultado dessa problemática é uma antinomia entre direitos fundamentais, sendo impossível estabelecer um parâmetro comum que os torne inquestionáveis.

As dificuldades em estabelecer um fundamento absoluto demonstram que o programa de Direitos Humanos, construídos a partir do século XVIII com a Declaração dos Direitos do Homem e do Cidadão pós Revolução Francesa, compõem um ideário político das classes sociais em ascensão. Tal fator, provoca um dissenso nos interesses de cada grupo sobre a possibilidade de uma fundamentação em comum que afastasse os antagonismos entre as diferentes categorias de direitos.

A multiplicidade de classes com diferentes interesses políticos, econômicos, sociais é, portanto, a primeira problemática que impede a existência de um fundamento universal. Os interesses e prioridades de cada grupo se confundem em relação ao que seria básico para o ser humano, gerando dissonância em relação ao próprio conceito de natureza humana enquanto cidadão que participa de determinada classe. Dessa forma, a construção histórica dos Declaração dos Direitos dos Homens liderada pela burguesia, 
demonstra a construção do conceito de cidadania vinculado aos grupos que patrocinaram a revolução.

Marx (2005, p. 50) é a principal referência crítica ao discurso universalista promulgado pela Revolução Francesa e à Declaração dos Direitos do Homem e do Cidadão. As críticas apresentadas por Marx surgem a partir de circunstâncias históricas da codificação alemã, partindo do pressuposto de "por que os judeus alemães do século XIX insistem em se inserir na sociedade?”, apresenta uma forma reconstruída da dialética, dessa vez, sob a metodologia do materialismo histórico.

Em seu ensaio "Sobre a questão judaica", distingue os direitos do homem dos direitos do cidadão, afirmando sobre a construção dos direitos na Revolução como produto da sociedade burguesa, aos moldes dos interesses da economia capitalista. "Os assim chamados direitos humanos, os droits de l'homme, diferentemente dos droits du citoyen, nada mais são do que os direitos do membro da sociedade burguesa, isto é, do homem egoísta, do homem separado do homem e da comunidade.” (MARX, 2005, p. 51)

A diferenciação entre os direitos do cidadão e direitos do homem pressupõe que os direitos do cidadão são vistos como "categoria da liberdade política", onde o seu conteúdo é medido pela participação na comunidade política e no sistema estatal, compondo uma categoria dos direitos humanos. Já os direitos do homem, são direitos civis e políticos presentes na Declaração, que propõe liberdades construídas pela burguesia e resulta em uma emancipação incompleta, já que não resolve a desigualdade real. (MARX, 2005, p. 51)

Assim, através do debate entre emancipação política e emancipação humana, é formulada a visão marxista sobre os direitos humanos, assim como o conceito de liberdade e as críticas ao universalismo da Declaração. Para Marx, a emancipação política é limitada porque ocorre dentro do Estado, sendo limitada pelo próprio Estado, e sob a égide do Estado, a liberdade sempre será tolhida.

Já a grande emancipação, dada como emancipação humana, acontecerá quando ninguém for dependente, afastando, inclusive, a necessidade de existência do Estado enquanto estrutura de organização do poder político.

Destarte, a construção do debate universalista alcança, no marxismo, uma dimensão emancipatória em relação ao homem enquanto ser humano, em seu estado 
natural, e enquanto cidadão, indivíduo participante de uma comunidade política. Tais fatores corroboram com a tese da antinomia de interesses entre os diversos grupos que compõem a sociedade, assim como heterogeneidade das demandas de classes diferentes.

Logo, a proposta de um fundamento para os Direitos Humanos, encontra sua primeira pretensão universalista negada ao analisar as diferentes composições de classes. Esse debate gera, como consequência, o próximo questionamento que diz respeito as diferentes cosmovisões que essas classes têm em relação ao que seria bom para si. Assim, as definições de fundamentos básicos sobre a natureza humana e os direitos inerentes a ela, variam.

A condição humana surge, então, como um desafio para a definição de um fundamento para os direitos humanos, pois a simples utilização da condição humana como pressuposto, sem acompanhar a elucidação do seu significado dentro da cultura na qual está inserida, gera um grau de abstração que pode levar a interpretações obscuras acerca do direito.

A globalização trouxe consigo a multiplicidade de problemáticas sociais e diferentes formas de concebê-las, a depender do grupo. Como seria possível definir a natureza humana em meio ao cenário de construção histórica de direitos? Assim, a ideia do fundamento universal torna-se muito mais abstrata. $\mathrm{O}$ debate filosófico acerca dos fundamentos humanos se tornou cada vez mais complexo no período pós-guerra, em decorrência do grande número de apátridas e minorias nacionais que já não se viam protegidos pelo estado que nasceram, enfrentando problemas que ameaçam a existência identitária e cultural.

Considerando o limiar existente entre a positivação dos Direitos Humanos através das Declarações e Convenções internacionais, e a verdadeira concretização dessas demandas a partir da especificidade dos grupos que compõem um estado-nação, o problema acerca de pretensões heterogêneas é inevitável. Neste sentido, Villey (2007, p. 7):

Para que sejam direitos de todos os homens, são codificados os direitos das mulheres, das pessoas idosas, das crianças (nos quais as ligas contra o aborto incluirão os direitos do feto), dos homossexuais, dos pedestres, dos motociclistas. Cada um deles fracionado em seus componentes: assim, do direito do homem ao lazer, os americanos tiraram um poético "direito ao sol" (direito de cada um e de cada uma a se bronzear em alguma praia da Flórida). 
Acrescentemo-lhe o direito à neve. Nesse registro, a imaginação de nossos contemporâneos é inesgotável;

As críticas ácidas apresentadas por Villey quanto ao sentido dos Direitos Humanos em meio a sua tecnificação como parâmetro norteador para o seu reconhecimento, dá-se o seguinte questionamento: os direitos humanos, em sentido técnico, são direitos? Entende-se, portanto, que "os direitos humanos não são "direitos" no sentido do positivismo jurídico, mas um ideal: modelos de realização da liberdade individual e de igualdade" (VILLEY, 2007, p.6)

O pensamento de Villey quanto a funcionalidade prática da lei é essencial. Ao retomar a discussão sobre o que é direito, resgata valores aristotélicos da justiça acerca das virtudes do cidadão, atualizando o debate sobre direito natural e o estado moderno. Em suas críticas, entende que os direitos humanos foram transformados em mera ideologia, perderam seu caráter de universalidade e individualidade. É uma síntese comum em seu pensamento, as denúncias a deturpação dos direitos humanos na sociedade contemporânea.

Elevar os direitos humanos a um gral de abstração que não pode ser obtido através de sua positivação é uma das conclusões que podem ser inferidas a partir dos desafios de sua fundamentação, seja pelas classes e seus diferentes interesses, ou pela dificuldade em estabelecer um conceito inquestionável de natureza humana que os torne universais e, sobretudo, exequíveis.

Em meio as discussões sobre a fundamentação dos direitos humanos, o universalismo e relativismo cultural surgem como referências clássicas acerca do paradoxo fundacional, onde a visão positivista-universalista da Declaração Universal demostrou a necessidade de considerar os direitos humanos como produtos culturais que precisam ser construídos considerando a peculiaridade de cada grupo.

Assim, a discussão já superada, de acordo com Bobbio (mas ainda não resolvida) acerca da possibilidade de existência de um fundamento universal, em contraponto com a necessidade de relevância cultural como antídoto as pretensões individualistas do liberalismo, avançaram para a questão da exequibilidade dos direitos humanos, sendo o universalismo e relativismo, parâmetros norteadores para a discussão crítica acerca tornalos universais, sem impor caráter universalista. 
Destarte, esses elementos que compõem o paradoxo central da fundamentação dos Direitos Humanos consistem no fato de que, por um lado, os Direitos Humanos são produtos culturais advindos de um contexto particular de problemas e por outro, de que há conceitos básicos que são feridos por práticas culturais, sendo ofensas aos direitos humanos.

A partir disso, seria possível questionar se determinada oriunda de uma tradição pode ser considerada uma lesão aos direitos humanos? Para responder esse questionamento, apresenta-se a clássica discussão entre universalismo e relativismo cultural dos direitos humanos, que possuem visões antagônicas em relação a forma de conceber os produtos culturais. Em seguida, o anti antirrelativismo de Geertz será apresentado como contrassenso a discussão clássica, onde a realidade de demandas por concretização comprova a necessidade de superar esse dualismo.

\section{O RELATIVISMO CULTURAL DOS DIREITOS HUMANOS}

A corrente relativista parte de críticas a falsa universalidade dos Direitos Humanos, que colocou-se em evidência ao final do século $\mathrm{XX}$, quando começaram a proliferar diversas convenções internacionais de Direitos Humanos, fundadas em um objetivo de atualizar a Declaração Universal, por motivos de novas demandas que estavam sendo incorporadas, como fatores ambientais, moradia, população, desenvolvimento, direito das mulheres e indígenas.

Surgiram, por exemplo, à Declaração dos Direitos da Criança (1959), Declaração sobre a Eliminação da Discriminação à Mulher (1967), Declaração dos Direitos do Deficiente Mental (1971), a Declaração dos Direitos Humanos do Islã, ratificada no Cairo em 1990. Tais convenções demonstrou a não-homogeneidade desses direitos para todos os estados participantes, o que provocou a realizações de outras convenções, para redefinir o pressuposto básico sobre direitos do homem, tentando positivar a peculiaridade das demandas.

A problemática da não-homogeneidade remete a discussão apresentada por Herrera Flores (2009) sobre os Direitos Humanos como produtos culturais. Parte-se do 
pressuposto de que toda formação constitui um processo cultural. Neste sentido, apresenta-se uma teoria pautada no relativismo relacional, onde todas as formas de relação com o mundo são consideradas como relações culturais, sendo essas relações consideradas "boas" ou "más", rompendo uma pretensão de uniformidade e homogeneização do mundo.

Nesse processo de reconhecimento cultural, Flores (2009, p.8-12) pretende ir além da simples aceitação do outro, elencando alguns desafios acerca da observação dos direitos humanos como produtos culturais, entre os quais:

1) Considera-se o fato de que todas as formações sociais contêm pautas culturais próprias para explicar, interpretar e intervir no mundo, sendo necessário reconhecer as peculiaridades dessas formas de vida;

2) Cada formação social possui uma forma particular de encaminhar as ações humanas para a dignidade; também há quem aceita a concepção hegemônica/dominante de dignidade, e os que se colocam em posição antagonista. Sendo, portanto, os modos de entender o mundo plurais e multiformes, havendo uma pluralidade de meios para alcançar a dignidade.

3) O universal deve ser, unicamente, a ideia de dignidade humana, diferenciandose a partir das formas de obtê-la. Neste sentido, o universalismo da dignidade não remete à imposição de uma forma particular, mas no desenvolvimento de maneiras adequadas onde todos os humanos possam empoderar-se.

4) Em cada formação social, determinadas atitudes e seus consequentes resultados podem ser vistas como potências ou obstáculos.

5) Os Direitos Humanos são produtos culturais que o Ocidente estabeleceu como padrão para alcançar uma vida digna em um contexto social imposto pela relação baseada no capital.

6) As reinvenções pelos Direitos Humanos consistem em ampliar as formas de compreensão, considerando-os como processos normativos, sociais, políticos, econômicos - que cultivem espaços de luta pela dignidade humana.

As críticas relativistas baseiam-se, principalmente, do argumento de que cada cultura tem sem modo individual de conceber as coisas, seus conceitos, tradições, costumes, lendas e histórias. Esse fator, provoca diferentes cosmovisões sobre o bem e o 
mal, transcendendo as barreiras do espiritualismo e misticismo, quando vistas sob a ótica de práticas ancestrais.

Além da relevância do contexto cultural, a observância dos Direitos Humanos como produtos culturais remete a sua utilização como ferramenta para reagir política, social, jurídica ou economicamente às demandas dentro do contexto que surgem e são legitimadas. Nesse contexto, os direitos humanos apresentam-se como propostas epistemológicas para uma filosofia da libertação que pretende aperfeiçoar uma discussão crítica sob a ótica do oprimido com viés descolonizador e antieurocentrista.

Assim, a visão universal, defendida pelos aclamadores da Declaração Universal e outras Convenções sobre Direitos Humanos subsequentes, refletem, nas críticas relativistas, uma visão Ocidental hegemônica de estabelecer critérios sobre a condição humana.

A proposta relativista pretende, então, opor-se a abstração ocidental na forma de conceber os Direitos Humanos positivados, criticando a racionalidade universal resultante do liberalismo em crise no período pós-guerra.

Assim, a Declaração Universal dos Direitos Humanos "padece do mal do relativismo", por ser fruto de tradições ocidentais que não representam outros povos e culturas. "O ponto é que há valores que de fato são particulares, como tais devem ser respeitados, desde que eles, naturalmente, não conflitem com os valores que são universais, que constituem o núcleo duro dos direitos humanos.” (SORTO, 2008, p. 12)

A pretensão universalista baseada na concepção ocidental dos direitos humanos pode ser vista como uma forma de colonialismo, a partir do momento em que surge um modelo que descaracteriza a produção cultural local em detrimento a pressupostos universais construídos em cada tradição cultural. Portanto, um dos pressupostos do relativismo em contraponto ao universalismo, é rompimento da concepção filosófica que nega o particularismo cultural, instigado por uma maneira de pensar influenciada pelo eurocentrismo do estado moderno, evidenciando os valores, as questões morais e as maneiras particulares de viver.

Entretanto, a simples afirmação de que os direitos humanos são "ideologia" vinculada a uma classe, não significa negar sua validade que alcance um valor mais universal, pois, apesar de ter surgido no Ocidente, os direitos humanos são, na atualidade, 
um programa global que reúne documentos internacionais e resoluções, que movimentam a sociedade civil, organizações não-governamentais e instituições democráticas. (TOSI, 2005 , p. 37 - 38)

Para analisar a fundamentação dos Direitos Humanos como produtos culturais e instrumento de emancipação, é imprescindível, como ponto de partida, discutir a modernidade europeia e seus frutos de colonização. Com o advento da modernidade, a sociedade europeia foi redefinida em novas estruturas fundamentais de organização material e simbólica, entre elas, o Estado, o pensamento racionalista e as relações econômicas capitalistas, das quais surgiram novas classes sociais. As novas relações de classe, junto à formação do sistema político e econômico, despertaram, também, novas formas de pensamento.

O relativismo também é, portanto, uma crítica ao liberalismo e sua maneira romantizada de conceber o mercado. A história econômica, desde o advento da Modernidade, sempre trabalhou pelo predomínio absoluto do mercado pelo capital, com respaldo da doutrina liberal que concebeu cegamente a característica de racionalidade do indivíduo, olvidando as demandas minoritárias e os ideais comunitários. Neste sentido, os Direitos Humanos também são concebidos como instrumento de emancipação econômica, que remete ao rompimento raízes históricas da colonização.

O relativismo como proposta de pensamento filosófico facilitou, assim, o debate crítico acerca do direcionamento tomado pelos Direitos Humanos durante no século XX, dando margem ao florescimento do multiculturalismo, como forma de reconhecer positivamente, no seio das Constituições, a coexistência de diversos povos e culturas em um determinado Estado-Nação, tentando preservar a especificidade cultural, moral e valorativa de cada grupo diante de suas práticas.

Parekh (2005, p. 336) demonstra que a relevância do papel da cultura é o ponto de partida adotado para demonstrar a fragilidade de uma visão universalista acerca da organização do sistema moral, reconhecendo que os seres humanos estão inseridos, desde o início da vida, em um mundo culturalmente estruturado e organizam suas relações sociais baseadas no sistema cultural carregado de significados pessoais.

Entendendo que diferentes culturas significam diferentes visões de mundo e existência, sendo a forma como cada um realiza suas práticas morais e intelectuais apenas 
uma parte da totalidade e inferindo que toda cultura é internamente plural e reflete um diálogo contínuo entre suas diferentes tradições e vertentes de pensamento.

No contexto latino-americano, as teorias relativistas são encontradas na ideia de construção das raças de Aníbal Quijano, e na hermenêutica diatópica de Boaventura de Sousa Santos (1997), que critica o universalismo justamente por encarar a cultura como uma barreira que o impede de avançar.

O debate relativista recebe destaque, no Brasil, nas obras de Gilberto Freyre (1959), como Ordem e Progresso, onde desmonta a história do patriarcado brasileiro, sendo influenciado por Franz Boas para ampliar a visão obre o convívio de diferentes raças no Brasil, dando ênfase as peculiaridades da cultural brasileira em detrimento de ideias que vão além de vertentes arianas e deterministas que fundamentam uma dominação eurocêntrica.

\section{O ANTI ANTIRELATIVISMO: UMA PROPOSTA DE CONTRASSENSO À DISCUSSÃo CLÁSSICA}

Usualmente em discussões acerca do relativismo dos Direitos Humanos, são levantadas hipóteses polêmicas que envolvem tradições de grupos específicos, como forma de criticar a posição relativista. É o caso da mutilação genital feminina, que de acordo com a Organização Mundial de Saúde, a prática está presente em 26 países do continente africano, alcançando cerca de 2 milhões de mulheres anualmente.

Dados da Organização das Nações Unidas apontam que, em todo o cenário internacional, o número de mulheres chega a 200 milhões. Em alguns casos, os pais pagam para mutilar suas filhas, a fim de evitar que sejam rejeitadas por homens que não querer mulheres circuncidadas, ou, pelo fato de o órgão feminino ser considerado impuro em alguns contextos culturais.

Também é o caso de algumas comunidades indígenas brasileiras, como os ianomâmis, que matam os bebês que nascem com alguma deficiência física. Associa-se a prática de infanticídio, todavia, no seio dessas culturas, esse ato não é considerado cruel.

Os exemplos acima ilustram alguns desafios do relativismo cultural que demostram a sua dificuldade de aceitação total, sendo necessário superar seus medos e desafios para poder 
criticar práticas culturais, ao invés de aceita-las cegamente, sob pena de torná-lo subjetivista, niilista, incoerente, maquiavélico ou uma estupidez estética. "O medo do relativismo conduziu a uma situação em que a diversidade cultural corresponde a uma série de expressões atribuídas a uma realidade da natureza humana, cujo a antropologia tenta discernir a essência dessa realidade". (GEERTZ, 2001, p. 61)

Destarte, antes de esclarecer os pressupostos do anti antirelativismo proposto por Geertz, é importante esclarecer alguns pontos em relação às críticas apontadas ao relativismo, como forma de demonstrar que a imposição do relativismo cultural entra em conflito com as bases da filosofia moral, principalmente no que diz respeito ao conceito de natureza humana.

Rachels (2004, p. 26) argumenta que o primeiro desafio enfrentado pelo relativismo diz respeito ao argumento das diferenças. O fato de não existir pressupostos objetivos sobre a moral, assim como a consequente falta de um padrão moral universal, faz com que nenhuma prática possa ser considerada, a priori, correta ou incorreta.

Desse modo, as diferenças podem ser apresentadas como desafio, tanto para o universalismo, quanto para o relativismo. Essa problemática gera, como consequência, o segundo desafio que diz respeito a criticar outras práticas culturais.

A partir do momento em que se aceita o relativismo cultural, em tese, a outra cultura adquire autonomia diante de seus rituais, práticas, costumes e atos. Assim, como seria possível conceber críticas, à luz dos direitos humanos, sobre essas práticas, já que o relativismo pressupõe a aceitação expressa de que não se deve interferir em outros grupos?

Aponta-se, portanto, outro desafio para o relativismo cultural que é discutir a questão da moralidade, a partir dos pressupostos da filosofia moral. A aceitação de qualquer prática alheia sob o argumento da manifestação cultural, gera uma presunção de que todas as condutas são corretas e aceitáveis, apesar de não existir um fundamento universal - o relativismo encontra-se em um beco sem saída. Esse problema dificulta, também, a percepção filosófica acerca do progresso moral, a partir do momento em que se afasta a moralidade para analisar uma tradição, já não seria possível analisa-la com a ideia de progresso.

É partindo desses pressupostos que Geertz (2001, p. 47) propõe-se a superar o medo do relativismo, conferindo valor antropológico à discussão, por entender que "a inclinação relativista está implícita no campo antropológico, todavia, o que parece um debate de implicações de pesquisas antropológicas, torna-se um debate sobre como viver com essas culturas" 
Dessa forma, $\mathrm{o}$ anti antirrelativismo consiste em uma ideia que ataca o antirrelativismo em ascensão, sem aderir ao relativismo, nem ao falso universalismo. No sentido de "objetar uma visão, em ver de defender a visão a que ela afirma se opor-se.", e considerando a possibilidade fornecida pela dupla negativa que permite rejeitar algo sem se comprometer com aquilo que este algo rejeita. (GEERTZ, 2001, p.48)

Ao considerar o relativismo um espectro que afugenta certos modos de pensar e direcionar para outros, percebe-se que pode haver algo mais convincente nesses modos pelos quais somos impelidos, principalmente por estarem ligados a tradições antropológicas. "Não foi o relativismo que matou a causalidade universal, foram os fenômenos instáveis dos quais eles ficaram impotentes.” (GEERTZ, 2001, p. 65)

Assim, o relativismo é visto como uma espécie de neorracialismo, que justifica o atraso técnico-econômico de povos que, outrora, foram colonizados. Aceitar a existência de determinada prática sob a justificativa de que "não há critério impessoal para reconhecer outra cultura", provoca, evidentemente, uma crise em relação a análise do progresso moral, a partir do momento em que os grupos estariam "condenados" eternamente a viverem sob determinados "dogmas".

Geertz entende que o cerne da discussão está no questionamento de como se deve entender os fatos indiscutíveis de cada cultura ao explicar seus rituais, analisar ecossistemas, interpretar sequências fósseis ou comparar línguas. Deste modo, a problemática central do relativismo gira em torno da tentativa - através de investigações biológicas, psicológicas, linguísticas, culturais - de restaurar os conceitos de natureza humana independente do contexto que está inserido.

Este fato provoca a mistura de perspectivas desordenadas que pressionam é direções diferentes, sendo necessário criticar os pressupostos básicos evidenciados em pesquisas, sem a intenção de questionar a validade de qualquer ciência, considerando que até "o natural pode ser antinatural quando pensamos na natureza 'em seu sentido pleno"”. (GEERTZ, 2001, p. 57)

Essa noção surge, a partir das ideias propostas pela crítica anti relativista, com o desenvolvimento de uma concepção de natureza humana que independa do contexto que esteja inserido, fazendo com que o relativismo vá além do "modo de ver as coisas" é, demonstrando o potencial de colocar a moral está acima da cultura, quando se trata de 
utilizar a natureza humana como fundamento básico. "A natureza humana como ideia reguladora foi sobretudo estimulada pelos avanços da genética e da teoria evolucionista, e da Mente Humana, pelos avanços da linguística, da informática e da psicologia cognitva.” (GEERTZ, 2001, p. 57 - 58)

Para isso, entende-se que é possível associar os "padrões comuns de comportamento genético" a "universal tendência do desvio". Ao invés de considerar o contexto cultural como justificativa primordial para determinada prática, considera-se pressupostos regulamentados pela natureza humana, em seus padrões e tendências de desvio.

Examinar dragões, ao invés de abominá-los, não domesticá-los ou afoga-los em barris de teoria é a proposta do o anti antirrelativismo. A intenção primordial de superar obstáculos do relativismo cultural, de modo que a natureza humana seja utilizada como parâmetro norteador que vai além do "modo de ver as coisas", demonstra a dificuldade em discutir os direitos humanos, desde pressupostos básicos, como o direito à vida e à dignidade, até demandas coletivas mais complexas, como direitos políticos.

Superar o debate clássico do universalismo e relativismo sem adotar uma posição exatamente enquadrada sobre qualquer dessas perspectivas é a ideia do anti antirrelativismo. No contexto de desenvolvimento de diferentes áreas da ciência, o conceito de natureza humana deve, então, ser complementado com saberes diversos.

E quando visto sob a perspectiva global da atual agenda dos direitos humanos, o processo científico acerca de respostas para os fenômenos culturais, a moral e o direito se torna uma construção que vai além de debates teóricos, influenciando na vida particular de cada cidadão do planeta, enquanto agente político de uma sociedade de construção, agente participativo da cultural onde está inserido e ser humano em busca da realização de suas garantias básicas inerentes a sua existência.

Analisar as ideias, reconhecer as demandas, debater sob o prisma da interdisciplinaridade são formar de ver o relativismo, sem colocar o véu que pode vir a cobrir os defeitos de produtos culturais. O debate acerca do aborto é o exemplo mais lúdico para expor os pressupostos do anti antirrelativismo.

O fato de aceitar a descriminalização do tipo penal e ser a favor de políticas públicas para mulheres que praticam o aborto, não torna ninguém necessariamente "próaborto". Portanto, adotar uma posição dualista em um debate de múltiplas visões, torna 
os direitos humanos uma arma ideológica que pode ser utilizada apenas sob dois vieses político-ideológicos, direita ou esquerda.

Setenta anos após a Declaração Universal dos Direitos Humanos, surgiram muito mais problemas do que solução sob o ponto de vista do debate crítico e das formas de apaziguar os conflitos sociais. Os direitos humanos ainda são mais vistos como cartas de recomendações da ONU e receitas que devem ser seguidas pelos países, fundamentado em um suposto consenso internacional, do que sob sua real necessidade de amparar suas demandas por concretização.

Conceber o anti antirrelativismo, traz o relativismo como uma ideia possível, a partir do momento em que pondera a produção cultural, com outros valores morais que vão além de uma forma simplista e dualista de ver as coisas. No contexto do globalismo, conceber a especificidade de uma cultura é um desafio, em meio a um padrão ocidental estimulado pelo american way of life que se afirma como forma mais verdadeira e correta de existir.

Ponderar valores é um dos processos descritos por Geertz, analogicamente, como examinar dragões. Quando referente aos direitos humanos, esses dragões são, tanto medievais, representados pelos gigantes jusnaturalistas, até os modernos como a liberdade, que lutam por espaço na arena dominada pelo capital.

Em meio a essa quantidade de dragões, o direito, que deveria ser a ferramenta de controle de todos os pressupostos analíticos, se esvai e perde o sentido em si mesmo, encontrando com outras ciências sociais para se complementar-se.

É nesse aspecto que os direitos humanos surgem como proposta emancipatória, para libertar das amarras tradicionais da modernidade, principalmente do ponto de vista científico, sendo a fonte de reconhecimento do ser humano como sujeito de direito, e sua cultura como produto essencial no processo de construção histórica. Examinar os dragões, dragões modernos e medievais, de todos os tamanhos e pensamentos, é o desafio do direito humano, principalmente porque agora, os direitos humanos são o ponto de partida, e não de chegada.

Não há mais o que discutir sua universalidade, há de se lutar por sua efetivação. E só o reconhecimento de sua importância que desperta o senso crítico capaz de ampliar 
o horizonte interpretativo dos direitos humanos, a fim de torná-los coerentes com os fundamentos de sua existência, sob pena de torná-los inexequíveis.

Compreender os direitos humanos a partir da complexidade de sua fundamentação estabelecer um parâmetro de aceitação que não se vincula, necessariamente, com determinado rótulo cultural e buscar a exequibilidade em suas demandas por efetivação, resgata questionamentos que perduram desde sua gênese histórica e filosófica, sendo um dos maiores desafios do século XXI.

\section{CONSIDERAÇÕES FINAIS}

A hipercomplexidade das sociedades contemporâneas traz desafios inéditos aos direitos humanos, que não foram sequer imaginados durante o desenvolvimento da Declaração Universal em 1948. Essa amalgamação dos direitos humanos com as lutas das minorias nacionais tornou-se o palco internacional para o desenvolvimento de um cenário humanista e progressista em relação ao amparo jurídico de pessoas, até então, alijadas dos processos de reconhecimento de suas demandas.

Refletir acerca dos direitos humanos, sua construção histórica, política e jurídica, assim como as lutas sociais que estão por trás dessa edificação tornou-se um compromisso ético como cidadão. É nesse ponto que a proposta anti antirrelativista torna-se necessária e urgente. Em meio a tantos discursos hegemônicos de grupos que estão diante do poder político e econômico que tentam deslegitimar as lutas populares, aceitar determinado posicionamento não significa ser, necessariamente, conivente com seu oposto.

Vive-se uma era onde tudo pode ser relativo e nada absoluto. Um simples caso jurídico pode tornar-se complexo na medida em que as partes demonstrem as peculiaridades por trás dos acontecimentos. Com os direitos humanos não é diferente. É necessário conhecê-los, muito além da tradição jurídica, respeitado a multiplicidade de conceitos e posicionamentos progressistas, e desconstruindo os pensamentos discriminatórios.

Em meio a dificuldade metodológica de definir um fundamento universal, o relativismo é a forma mais adequada de enxergar os direitos humanos como produtos de uma cultura, todavia, não deve ser utilizado de forma intransigente, sob pena de torna-se niilista, subjetivista e contraditório. 
$\mathrm{O}$ anti antirrelativismo como proposta metodológica que defende a antítese em forma de contrassenso, demonstra que as críticas ao relativismo não colocam, necessariamente, o argumento em posição universalista, podendo ser um elo de construção multidimensional entre as diferentes visões de mundo, regulada pelo ideal de natureza humana, evidentemente em avanço em outros campos científicos como a neurociência, linguística e informática.

Nesse contexto de luta, valorizar os direitos humanos e suas diferenças, é reafirmar sua importância histórica como meio de impedir as atrocidades da Segunda Guerra Mundial. Considerar sua especificidade diante do meio que está inserido é, então, uma forma de reafirmar que cada valor individual é válido para resgatar o humanismo das ciências jurídicas.

Em outros termos, a saída do dualismo clássico entre universalismo e positivismo, permite o reconhecimento dessas demandas muito além da forma que eles são. Possibilita mergulhar a fundo nas formações culturais, conhece-las, investiga-las, re-conhecê-las, e permitir sua afirmação diante de valores fundamentais, assim como sua negação diante de atitudes violentas e intransigentes, que podem tornar os direitos humanos verdadeiras ferramentas de dominação de culturas hegemônicas em detrimento das minorias.

\section{REFERÊNCIAS}

BOBBIO, Noberto. A era dos direitos. Rio de Janeiro: Editora Campus, 1992.

DOUZINAS, Costa. O fim dos direitos humanos. São Leopoldo: Unisinos, 2009. FLORES, Joaquín Herrera. Teoria Crítica dos Direitos Humanos. Rio de Janeiro: Editora Lumen Juris, 2009.

FEITOSA, Enoque. Cidadania, Constituição e Desenvolvimento: a tensão, no direito, entre promessas formais e as demandas por concretização. In: Revista Jurídica UNICURITIBA, vol. 04, n. 45. Curitiba: 2016. p .24 - 39.

FREYRE, Gilberto. Ordem e Progresso. Rio de Janeiro: José Olímpio, 1959.

LOSURDO, D. Contra-História do Liberalismo. Aparecida: Ideias e Letras, 2006.

MARX, Karl. A Questão Judaica. 5a edição. São Paulo: Centauro, 2005. 
GEERTZ, Clifford. Anti anti-relativismo. In: Nova Luz sobre a Antropologia. Rio de Janeiro: Jorge Zahar, 2001.

PAREKH, Bhikhu. Rethinking Multiculturalism. Cultural diversity and political theory. Basingstock: Palgrave Macmillan, 2005.

RACHELS, James. Elementos da Filosofia Moral. $1^{\text {a }}$ ed. Lisboa: Editora Gradiva, 2004.

SANTOS, Boaventura de Sousa. Uma concepção multicultural de direitos humanos. v. 39. São Paulo: Revista Lua Nova, 1997.

SORTO, Fredys Orlando. A Declaração Universal dos Direitos Humanos no seu sexagésimo aniversário. In: Verba Juris, Anuário da Pós-Graduação em Direito, vol. 1. 2002. João Pessoa: Programa de Pós Graduação em Ciências Jurídicas, 2008. p. 9-34.

TOSI, Giuseppe. Direitos Humanos: reflexões iniciais. In: TOSI, Giuseppe. (Org.). Direitos Humanos: história, teoria e prática. João Pessoa: Universitária, 2005.

VILLEY, Michel. O Direito e os Direitos Humanos. São Paulo: WMF Martins Fontes, 2007. 